\title{
The Democratic Effect of Direct Democracy
}

\author{
LUCAS LEEMANN University College London \\ FABIO WASSERFALLEN University of Salzburg \& University of Zurich
}

\begin{abstract}
$A$ key requirement of democratic governance is that policy outcomes and the majority preference of the electorate are congruent. Many studies argue that the more direct democratic a system is, the more often voters get what they want, but the empirical evidence is mixed. This analysis explores the democratic effect of initiatives and referendums theoretically and empirically. The prediction of the formal model is that "bad" representation (i.e., a large preference deviation between the electorate and the political elite) is good for the democratic effect of direct democracy. An empirical investigation of original voter and elite survey data, analyzed with multilevel modeling and poststratification, supports this argument. Building on the literature, the findings of the analysis suggest that the extent to which direct democratic institutions are conducive for policy congruence-and may thus be advisable as democratic correctives to representative systems-depends on the political conflict structure.
\end{abstract}

I assume that a key characteristic of a democracy is the continuing responsiveness of the government to the preferences of its citizens (Dahl 1971, 1).

\section{INTRODUCTION}

A

core element of a democracy is the alignment of legislative and government actions with voters' preferences. The normative idea that public policies should reflect the majority will of the electorate, what we define as policy congruence, is as a general democratic principle hardly contested. Two literatures approach the study of policy congruence from different angles. First, representation scholars argue that the overlap between the preferences of the electorate and those of the political elite is the key driver of policy congruence (Golder and Stramski 2010; Miller and Stokes 1963). Second, the literature on direct democracy argues that referendums and initiatives are conducive for policy congruence because voters are supposed to get what they want when they can participate in policy making (Gerber 1996; Matsusaka 2010). However, the empirical evidence on the positive effect of direct democratic institutions on policy congruence is mixed (Lax and Phillips 2012). For understanding the conditions under which direct demo-

Lucas Leemann is Lecturer, Department of Political Science, University College London, United Kingdom (lleemann@gmail.com). URL: www.lucasleemann.ch.

Fabio Wasserfallen is Assistant Professor, University of Salzburg, Austria \& Senior Research Associate, University of Zurich, Switzerland (fabio.wasserfallen@sbg.ac.at). URL: www.fabiowasserfallen. ch.

Werner Seitz and the Swiss Federal Statistical Office kindly supplied us with census data and the Swiss National Science Foundation financed the voter survey (Grant No. 137765; project with Fabrizio Gilardi). We also would like to thank Sheri Berman, Daniel Bochsler, Sebastian Fehrler, Fabio Franchino, Fabrizio Gilardi, John Huber, Dominik Höglinger, Jeff Lax, Isabela Mares, Nolan McCarty, Pierce O'Reilly, William Ossipow, Marco Steenbergen, Alois Stutzer, Julian Wucherpfennig, Reto Wüest, and the participants of the Columbia graduate student comparative politics working group for insightful comments. Lucas Leemann acknowledges the support from the Swiss National Science Foundation (P1SKP1-148357), and Fabio Wasserfallen acknowledges a Fung Global Fellowship at Princeton University. cratic institutions are conducive for policy congruence, this analysis focuses on the policy preferences of the electorate and the political elite.

To that end, we provide a formal and empirical analysis. The formal model predicts that the more the preferences of the political elite and the electorate deviate from one another, the larger is the positive effect of initiatives and referendums on policy congruence. Thus, in contrast to the argument of the representation literature, "bad" representation is conducive for the direct democratic effect on policy congruence. Why is that? In essence, initiatives and referendums are powerful democratic correctives when the political elite has clear signals that the voters hold deviating preferences. For the empirical investigation of that argument, we analyze the variation in direct democratic institutions among Swiss cantons (which are in many other dimensions comparable polities). To derive preference measures, we conducted two surveys asking cantonal politicians and voters whether they support a total of 10 tax, health-care, education, and family policies. With these data and fine-grained census information, we estimate elite and voter preference measures, as well as the deviations between the two, using multilevel modeling and poststratification (Gelman and Little 1997; Park, Gelman, and Bafumi 2004).

This study makes a substantial contribution to the literature on direct democracy by providing an empirical investigation that relies on consistent measures of policy congruence and accurate estimates of the preferences of the electorate and the political elite over various policy areas. The findings of the empirical analysis support the theoretical prediction that, in direct democratic systems, a large deviation between the preferences of the political elite and the voters is good for policy congruence, not bad, as the representation literature suggests. In a nutshell, direct democratic institutions have no effect on policy congruence when the electorate's and the elites' preferences are aligned; when they deviate, however, referendums and initiatives exert a positive effect on policy congruence, and the conducive effect grows as the elite-voter preference deviation becomes larger. The core substantive contribution of the analysis is that we show how the 
conducive effect of direct democracy on policy congruence depends on the elite-voter preference deviation, which may, at least partly, explain the mixed empirical findings of the literature.

Last but not least, we discuss the institutional implications of our findings by exploring the political conflict structures under which direct democratic institutions can fully exploit their potential for increasing policy congruence. Our analysis builds on the insights of the representation and the direct democracy literatures, which suggest that competitive and fair elections are powerful in minimizing the elite-voter preference gap on the main political conflict dimension, while direct democratic institutions allow the unbundling of issues and are thus effective democratic correctives for policy questions on second-ordered dimensions (Besley and Coate 2008). Accordingly, in a polity with a onedimensional policy space (e.g., the United States), the conducive effect of direct democracy should be limited because it only matters for the rare policy questions that are not on the main conflict dimension. However, in systems with multiple conflict dimensions, where, for example, the political conflict on cultural policy questions is clearly distinct from the main left-right conflict dimension (e.g., many European countries), we expect strong positive effects, because initiatives and referendums can democratically accommodate a larger number of policy questions on second-ordered dimensions. In sum, the findings of the literature and our analysis suggest that the extent to which direct democratic institutions are advisable as democratic correctives to representative systems depends on the political conflict structure.

The remainder of this article is structured as follows: first, the next section derives the theoretical model; we then discuss the measuring of voters' and elites' preferences, the data, and the empirical design, before presenting the empirical analysis (including instrumental variable regressions); the section subsequent to the theoretical and empirical analysis discusses the institutional implications of our findings; and the final section concludes.

\section{THEORY}

We approach the analysis of policy congruence with a theoretical model that shows how the mechanism of direct democracy interacts with the elite-voter preference deviation. The stylized model of policy production analyzes the effects of direct democracy under the scenarios of "good" representation (i.e., a small preference deviation between the elite and the voters) and "bad" representation (i.e., a large deviation). There are a number of formal analyses of direct democracy that explore the initiative and referendum processes in a continuous policy space, whereas the policy can be set arbitrarily far away from an ideal point (Gerber 1996; Hug 2004; Lupia 1992; Romer and Rosenthal 1978; Streunenberg 1992). Following Besley and Coate (2008), we adopt a discrete policy space (i.e., a law is either in place or not). The discrete policy space has several advantages: first, the actors' decision set is reduced to a discrete choice, which is the kind of decision voters face at the ballot box; second, the model can account for referendum and initiative processes; and, third, the discrete policy space allows us to estimate the preferences of the political elite and the electorate on a common scale and thus to derive consistent measures for policy congruence and preference deviations (see empirical analysis).

The model includes two players, the government $(G)$ and the voters $(V)$, which both have preferences measured on a continuous scale that represents the degree of support for a specific binary policy decision (e.g., the introduction of a smoking ban). ${ }^{1}$ The game starts with a specific law being present or not. The government moves first by choosing between two options: either to maintain the status quo or to propose a policy change. In a second step, the voters either accept the government's move or, in case they disagree, they may use direct democratic rights (i.e., calling for a referendum, if the government introduced a new law, or launching an initiative, if the government maintained the status quo). ${ }^{2}$ If the voters use direct democratic action, the government will lose the vote, and the majority of the electorate will be satisfied. Figure 3 in Appendix A1 shows the game tree of this strategic interaction.

The use of direct democratic rights is associated with costs for the voters, as they have to collect the necessary amount of signatures $\left(c_{V}\right)$. In addition, both the government $\left(c_{G}\right)$ and the voters $\left(c_{V}\right)$ have to pay campaign costs in case of a popular vote. ${ }^{3}$ Accordingly, we write the following linear and symmetric utility functions for the government and the voters:

$$
\begin{aligned}
& U_{G}=-\left|x_{\text {out }}-x_{G}\right|-I_{d d} \cdot c_{G}, \\
& U_{V}=-\left|x_{\text {out }}-x_{V}\right|-I_{d d} \cdot c_{V},
\end{aligned}
$$

where $I_{d d}$ denotes the use of direct democratic institution $\left(I_{d d}=1\right.$ if the voters call for a referendum or launch an initiative; $I_{d d}=0$ if the voters do not take action). The final policy outcome $\left(x_{\text {out }}\right)$ can either be 1 or 0 , depending on whether the law is on the books or not. The continuous preferences of the government $\left(x_{G}\right)$ and the voters $\left(x_{V}\right)$ range from 0 (no support) to 1 (full support). The electorate knows the preference of the government, which acts first and communicates its position in the legislative process. The government, however, does not know precisely the preference of the voters when it decides to change a law, because government officials do not survey constantly the

\footnotetext{
${ }^{1}$ We analyze the government as the relevant player of the political elite because we empirically investigate Swiss cantons, where the governments are considered more powerful than the parliaments (Vatter 2002).

${ }^{2}$ Our model only has two players (there is no opposition using direct democratic rights). This simplification would only be problematic if there were no organized political group that would collect signatures for a referendum or an initiative in case the majority of voters disagrees with the government.

${ }^{3}$ The model does not consider electoral costs for the government in taking no action or proposing new laws.
} 
preferences of the electorate, and they cannot fully anticipate the dynamics of a potential campaign (Hug 2004; Matsusaka and McCarthy 2001; Romer and Rosenthal 1979). Accordingly, the model assumes that the government acts based on a belief of how strong the support in the electorate will be. Technically speaking, the government receives a noisy signal, $\hat{x}_{V}$, which it uses to form a belief about the voters' support for a law. The belief follows a beta distribution (ensuring nonzero probability values between 0 and 1 ) with an unbiased estimate of the true preference as expected value $\left(\mathrm{E}\left(\hat{x}_{V}\right)=x_{V}\right) \cdot{ }^{4}$

For identifying the conditions of an equilibrium, we assume that a policy does not exist, and we start with the electorate's decision to use direct democratic rights (the last step of the game). ${ }^{5}$ In case the government prefers the status quo, the voters decide whether they want to launch an initiative for the introduction of a new law. ${ }^{6}$ The voters' utility from launching an initiative is $=-\left|1-x_{V}\right|-c_{V}$, and their utility from not launching an initiative is $=-\left|0-x_{V}\right|$. They will collect signatures for a public vote whenever $x_{V} \geq \frac{1+c_{V}}{2}$ (condition 1); that is, when the support within the electorate $\left(x_{V}\right)$ is greater than the costs of launching an initiative $\left(c_{V}\right)$. In case the government proposes a new law, the voters decide whether they want to block the legislation with a referendum. The voters' utility from calling a referendum is $=-\left|0-x_{V}\right|-c_{V}$, and their utility from not calling a referendum is $=-\left|1-x_{V}\right|$. They will collect signatures for a public vote whenever $x_{V} \leq \frac{1-c_{V}}{2}$ (condition 2); that is, when the costs for calling a referendum $\left(c_{V}\right)$ are low enough compared to the preference $\left(x_{V}\right)$. The bottom line of conditions 1 and 2 is that the electorate weighs its preference against the costs of using direct democratic rights.

The first move in the game-namely, the government's decision to propose a policy change-is a function of the two discussed conditions that specify whether the voters will use direct democratic rights. As discussed earlier, the government acts based on its beliefs about the voters' preference $\left(\hat{x}_{V}\right)$. The government's decision of whether it should propose a new policy depends on its own preference for a new law $\left(x_{G}\right)$, the costs of a potential public vote $\left(c_{G}\right)$, and the anticipated probability that the voters will use direct democratic institutions. ${ }^{7}$ A detailed derivation of the inequalities is presented in Appendix A1. Formally expressed, the government introduces a new law, if

\footnotetext{
${ }^{4}$ The first shape parameter is a function of $x_{V}$ and the second is constant (e.g., $s_{2}=30$ ). Accordingly, as $x_{V}$ increases, the government assigns higher probabilities to higher values for $x_{V}\left(\frac{\partial F\left(x_{V}\right)}{\partial x_{V}}>0\right)$.

${ }^{5}$ For the equilibrium solutions of the opposite scenario, see Appendix A1.

${ }^{6}$ As in other models of direct democracy, the government always loses in equilibrium when the voters call for a public vote because direct democratic rights are only used in case of an electoral majority (e.g., Hug 2004).

7 The government's belief of $x_{V}$ feeds into the expected probability of a referendum. The belief follows a beta distribution and condition $2\left(x_{V} \leq \frac{1-c_{V}}{2}\right)$ provides $p_{\text {ref }}=\int_{x_{V}=0}^{\frac{1-c_{V}}{2}} \frac{x_{V}^{\alpha-1}\left(1-x_{V}\right)^{\beta-1}}{B(\alpha, \beta)}$, whereas $\alpha$ and $\beta$ are the shape parameters and $B(\cdot)$ is the beta function.
}

condition 3 holds:

$$
x_{G} \geq \frac{p_{\text {ref }} \cdot\left(c_{G}-1\right)-p_{\text {ini }} \cdot\left(c_{G}+1\right)+1}{2\left(1-p_{\text {ref }}-p_{\text {ini }}\right)},
$$

where $p_{\text {ini }}$ and $p_{\text {ref }}$ denote the probability that the voters will launch an initiative or call for a referendum, which depends on voters' preference and their costs of using direct democratic rights (conditions 1 and 2). Condition 3 states that the government's decision to introduce a new law is a function of its own and the voters' preferences as well as the usage costs of direct democratic institutions. This condition suggests, for example, that the government may propose laws that deviate from the majority view of the electorate, when the costs for the voters to launch a referendum are high enough. ${ }^{8}$ Based on the derived conditions, we investigate how the costs of using direct democratic rights affect the probability that policies are congruent with the majority preference of the median voter, and whether the effect of direct democracy on policy congruence is mediated by the government-voter preference deviation. To that end, we run simulations with the following simulation parameters:

- The government has a strong preference for introducing a new policy $\left(x_{G}=0.7\right)$.

- The support within the electorate for the policy varies between 0.1 and $1.0\left(x_{V} \in(0.1,1.0)\right)$.

- The costs of using direct democratic rights are either moderate or high $\left(c_{V}=\{0.35,0.5\}\right)$.

- To account for the government's probabilistic beliefs regarding voters' preference, we simulate 1,000 times $x_{V}$. The shape parameters are $s_{1}=\frac{x_{V} \cdot s_{2}}{1-x_{V}}$ and $s_{2}=30$ (see footnote 4 ).

Figure 1 plots the comparative statics. The top plot shows how the probability of policy congruence varies as a function of voters' preferences. The preferences of the median voter and the government are congruent in the area where the majority of the electorate supports the new policy $\left(x_{V}>0.5\right)$. In that area, the law will be introduced and the policy outcome is congruent with the majority preference of the voters (see the $100 \%$ probability of policy congruence on the right side of the upper plot). More interesting is the situation in which the preferences of the voters and the government deviate; that is, when $x_{V}<0.5$. When only a few voters support a new policy, the government will not introduce the policy because it anticipates that the electorate will veto the proposal with a referendum due to the strong popular resistance, and the resulting nonadoption of the policy is congruent with the will of the median voter (see the $100 \%$ probability of policy congruence on the left side of the upper plot). However, as the resistance within the electorate decreases (i.e., the voters' support for the policy increases), the lines start falling: the probability of policy congruence decreases because

\footnotetext{
${ }^{8}$ Appendix A2 presents the comparative statics and two plots for illustrating the key aspects of the model.
} 


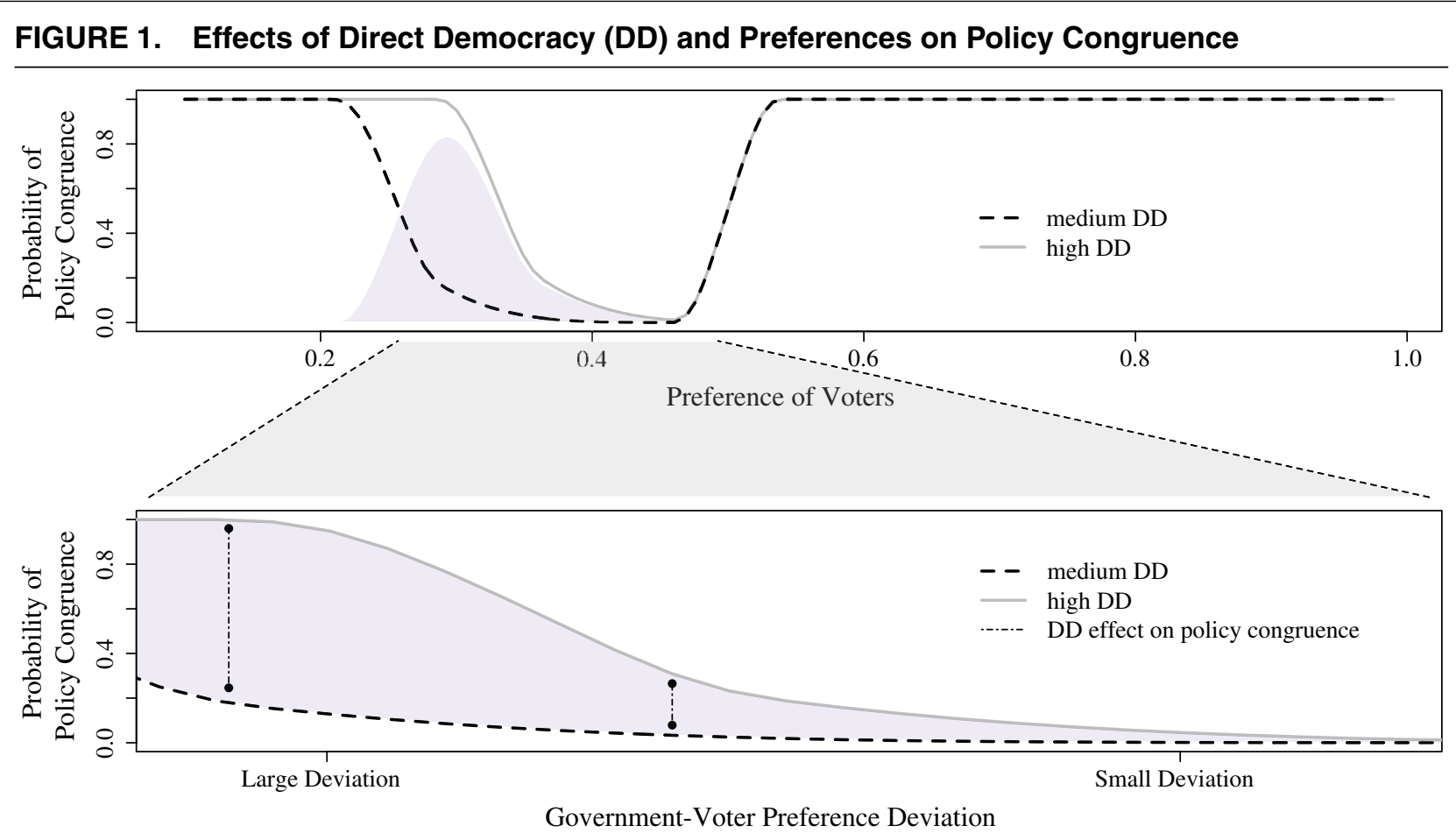

Notes: Government preference: $x_{G}=0.7$; medium cost (medium DD): $c_{V}=0.5$; low cost (high DD): $c_{V}=0.35$.

the voters start refraining from blocking the new law, although the majority still opposes the new law.

For highlighting the effects of direct democracy on policy congruence, we manipulate the costs of using direct democratic rights $\left(c_{V}\right)$. The dashed black line shows the findings for a medium level of direct democracy and the gray line for a high level of direct democracy. The dashed line starts falling when the support in the electorate is at about only $20 \%$, while the turning point of the gray line (where $x_{V}=\frac{1-c_{V}}{2}$ ) is at a electoral support of about $30 \%$. Thus, the more direct democratic a system is, the better the voters are shielded from being overruled by a deviating preference of the government. ${ }^{9}$ The worst situation, from a policy congruence perspective, is when a bare majority of the electorate are against the government's proposal. In that case, the voters will not overturn the government's decision, even when the costs for calling a referendum are low. The lower plot highlights the most interesting range between the turning point of the gray line and the area before the electorate and the government share the same view. The variation of

\footnotetext{
${ }^{9}$ If the government's uncertainty about voters' preferences decreases, the turning points of the lines will remain the same. What changes is that the curves fall and rise faster. In the presented simulation we modeled the second shape parameter to be fairly large $\left(s_{2}=30\right)$. The plotted curve for medium direct democracy shown in Figure 1 starts falling from $100 \%$ predicted policy congruence at the voters' support of $20 \%$ and hits the $0 \%$ probability of policy congruence, where the voters' support is at $40 \%$. If we decrease the government's uncertainty, by setting $s_{2}=1$, the falling part of the curve is between the more narrow range of $23 \%$ to $28 \%$ voters' support.
}

voters' resistance against the new policy is equivalent to the variation of the government-voter preference deviation (the government's support for the policy is constant at $\left.x_{G}=0.7\right)$. The lower plot shows that as the preference deviation increases, the positive effect of direct democracy on policy congruence becomes larger.

Based on the presented findings, we formulate the following theoretical predictions:

- Policies will be congruent with voters' majority preference, if the government and the voters share the same preference.

- Direct democratic institutions have a conducive effect on policy congruence, if the preferences of the government and the voters deviate.

- If the preferences of the government and the voters deviate, the positive effect of direct democracy on policy congruence increases as the deviation grows.

The first two predictions-namely, that policies will be congruent when the elite and the voters share the same preferences and that direct democracy has a positive effect on policy congruence - are quite well established in the literature..$^{10}$ Our third prediction, however, that the size of the positive direct democratic effect on policy congruence depends on the elite-voter preference deviation is novel and interesting, as it suggests that in direct democratic systems a large preference

\footnotetext{
$\overline{10}$ For an exception, see Besley and Coate $(2008,392)$, who predict a negative effect of direct democracy on policy congruence under specific circumstances.
} 
deviation is good (not bad) for policy congruence. In other words, the direct democratic mechanism of policy congruence works better under the scenario of "bad" representation (i.e., a large preference deviation), essentially because a large deviation provides clear signals to the government on the preferences of the voters. The mechanics of the theoretical model suggest that the main effect of direct democracy on policy congruence is that the political elite anticipate preference deviations and, in the case that voters have extensive direct democratic rights, follow the position held by (the large) majority of voters. This institutional effect of direct democracy is often referred to as the indirect effect of direct democracy-as opposed to the direct effect, where the actual use of direct democracy drives the policy outcome. A strength of the presented theory is that the key variables (the actors' preferences and the costs of direct democracy) are operationalizable, and we can thus empirically test the theoretical predictions.

\section{MEASURING VOTERS' AND ELITES' POLICY PREFERENCES}

The key for the empirical analysis of our arguments is that the policies and preferences are measured on the same metric. This is the case in our investigation, as we rely on elite and voter surveys with binary questions that were designed and executed for this research. We asked Swiss voters and politicians whether they support or reject 10 policies that cantons either have or do not have (for the importance of using a binary metric, see Achen (1978); Erikson, Wright, and McIver (1993); Hug (2011); Matsusaka (2001)). The 10 questions cover the most controversial policy questions of the main policy areas in the competence of the cantons, such as tax, family, immigration, education, and health-care policies. The surveys included questions on, for example, the progressivity of cantonal taxes, the voting rights of foreigners, and smoking bans (Appendix A3 lists all policy questions). ${ }^{11}$ The broad policy spectrum is important, as it allows us to rule out that our empirical findings are biased because we selected specific policy areas.

We estimate voters' policy preferences on the cantonal level with national survey data from 1,507 respondents. Measures for subnational units cannot be estimated by disaggregating the national survey data, as there are only very few observations for some cantons (Levendusky, Pope, and Jackman 2008; Warshaw and Rodden 2012). Thus, we take advantage of recent developments in survey research by using multilevel regression and poststratification (MRP), which provides good estimates, even when the samples for individual subnational units are small (Gelman and Little 1997; Kastellec, Lax, and Phillips 2010; Lax and Phillips 2009a; 2009b; 2012; Pacheco 2012; Park, Gelman, and Bafumi 2004; Tausanovitch and Warshaw 2013; Warshaw and Rodden 2012). MRP estimates the preferences of small constituencies in four steps. The first

\footnotetext{
11 The survey was conducted in June 2012 with CATI.
}

step is to conduct a survey that collects, besides the policy questions, minimal personal information of the respondents (survey step); in the second step, a hierarchical model is fitted to the data to make predictions for specific hypothetical voters (response model step); in the third step, the model estimates are used to make predictions for predefined hypothetical voters (prediction step); finally, based on fine-grained census data, researchers calculate constituency support by weighting the estimated preference of each hypothetical voter according to the number of voters who have the same characteristics as the hypothetical voter in a specific constituency (poststratification step).

For identifying voter categories, we include gender, education (six categories), domicile type (four categories), and age (four groups). Altogether, this yields for each canton 192 distinct types of voters $(2 \times 6 \times 4 \times 4)$. In the hierarchical model (response model step), we include random effects for the four individual-level variables. Moreover, we add cantonallevel variables, such as the share of German speakers and of left party support, denoted by the matrix $\mathbf{X}$, and we account for regional variation. ${ }^{12}$ Finally, we include a cantonal random effect, a fixed effect based on $\boldsymbol{\beta} \mathbf{X}$, and a random effect for the region. ${ }^{13}$ The model is specified as follows:

$$
\begin{aligned}
& \operatorname{Pr}\left(y_{i}=1\right)= \Phi\left(\beta_{0}+\alpha_{j[i]}^{\text {gender }}+\alpha_{k[i]}^{\text {education }}\right. \\
&\left.+\alpha_{l[i]}^{\text {domicile }}+\alpha_{m[i]}^{\text {age }}+\alpha_{n[i]}^{\text {canton }}\right) \\
& \alpha_{j}^{\text {gender }} \sim N\left(0, \sigma_{\text {gender }}^{2}\right), \text { for } j=1,2 \\
& \alpha_{k}^{\text {education }} \sim N\left(0, \sigma_{\text {education }}^{2}\right), \text { for } k=1, \ldots, 6 \\
& \alpha_{l}^{\text {domicile }} \sim N\left(0, \sigma_{\text {domicile }}^{2}\right), \text { for } l=1, \ldots, 4 \\
& \alpha_{m}^{\text {age }} \sim N\left(0, \sigma_{\text {age }}^{2}\right), \text { for } m=1, \ldots, 4 \\
& \alpha_{n}^{\text {canton }} \sim N\left(\alpha_{o[n]}^{\text {region }}+\boldsymbol{\beta} \mathbf{X}_{n}, \sigma_{\text {canton }}^{2}\right), \text { for } n=1, \ldots, 26 \\
& \alpha_{o}^{\text {region }} \sim N\left(0, \sigma_{\text {region }}^{2}\right), \text { for } o=1, \ldots, 7
\end{aligned}
$$

MRP takes advantage of the data structure, as we estimate a hypothetical voter's predicted support for a policy, based on all the people in the sample who share

\footnotetext{
12 Education categories: 1 (mandatory schooling or no response), 2 (apprenticeship), 3 (university-entrance diploma [Matura], teachers college), 4 (additional job training [höhere Fachausbildung]), 5 (Advanced training [Höhere Fachhochschule]), 6 (university degree including U. of App. Sciences); Domicile categories: 1 (urban center), 2 (agglomeration), 3 (isolated city), 4 (rural area); Age categories: 1 (18-34 years), 2 (35-49 years), 3 (50-74 years), 4 (75- years); $R e-$ gion categories: 1 (Geneva, Valais, Vaud), 2 (Bern, Fribourg, Jura Neuchâtel, Solothurn), 3 (Aargau, Basel-Stadt, Basel-Landschaft), 4 (Zurich), 5 (Appenzell I. Rh., Appenzell A. Rh., Glarus, Grisons, St. Gallen, Schaffhausen, Thurgau), 6 (Lucerne, Nidwalden, Obwalden, Schwyz, Uri, Zug), and 7 (Ticino).

13 To specify the best (not overfitted) response model, we estimated for each policy question 64 combinations of five different cantonal predictors and chose the models that minimize AIC and BIC. For more detailed information on the model specifications, see Appendix A4.2.
} 
her attributes. Concretely, when we estimate whether a 55-year-old woman with a university degree, who lives in a rural village, supports a policy or not, we use information from the entire sample, but the estimates are especially influenced by the answers from the 50to 64-year-old respondents, the university degree holders, the people living in rural areas, and the women. The property of partial pooling is key for the accuracy of MRP, as we rely neither solely on the average for all voters of a canton, nor on the average of the entire sample, but rather on the weighted mean of the two averages (Gelman and Hill 2007; Steenbergen and Jones 2002).

Using the model estimates, we carry out steps 3 and 4 (prediction for all hypothetical voters and poststratification with census data). We have 192 different hypothetical voters in each canton. For each of these hypothetical voters, the model predicts the probability with which these voters support a policy. Since we have in addition information about the variation among cantons, we create predictions $\left(\hat{\pi}_{n g}\right)$ for all hypothetical voters in each canton. In the final step (poststratification), we sum the predicted support among all hypothetical voters and weigh each type by its frequency in a given canton $\left(N_{n g}\right)$ with data from the census $\left(N_{n}\right.$ is the total number of eligible voters):

$$
\hat{\pi}_{n}=\frac{\sum_{g \in n}^{G} \hat{\pi}_{n g} N_{n g}}{N_{n}} .
$$

Following these four steps, we estimate the cantonal support of the electorate for each policy. Besides the cantonal preference of voters, we also estimate the preference of the elite (i.e., the cantonal governments) with the same method. To that end, we conducted an online survey with cantonal politicians. The survey asked cantonal politicians about their preferences for the 10 policies under investigation. We selected politicians from cantonal parties that represent more than $10 \%$ of the electorate. The final sample consists of 431 respondents. Thanks to a targeted follow-up survey, the sample includes at least three respondents for each cantonal party in the sample. ${ }^{14}$ We again apply the four steps of the MRP method to derive cantonal elite preferences using the elite survey data on the policy preferences of the cantonal politicians. However, for the estimation of the elite preferences, we use a hierarchical model specification and weights for the poststratification that are tailored to the application of MRP for cantonal elite preferences. The elite hierarchical model includes the party affiliation of cantonal politicians as an individual-level variable, which is a very strong predictor of whether a cantonal

\footnotetext{
${ }^{14}$ For the first online survey wave on March 15, 2013, we invited 1,046 cantonal politicians with personalized emails to participate in the survey. After analyzing the sample of the first wave, we contacted, on March 28, 2013, 99 additional cantonal politicians from the yet under-represented cantonal parties (again with personalized emails) Of the total 476 received responses, we dropped 45 from the sample as they either included impossible canton and party combinations or were double entries. The final sample consists of 431 respondents ( $38 \%$ of the 1,145 contacted politicians).
}

politician supports a policy or not. In addition, we again model cantonal-level variables and random effects for the cantons and for the regions in the response model. ${ }^{15}$

In the next (third) step, we predict for each cantonal party the policy preferences with the specification of the elite hierarchical model. Finally, in the poststratification step, we derive aggregated cantonal elite preference measures that are representative of the political strength of the relevant parties in each canton. To that end, we weigh the predicted cantonal party preferences with the government compositions of each canton. In short, we estimate cantonal elite preferences for all 10 policies by first predicting policy support within each relevant cantonal party based on our elite survey data, before aggregating the estimated party preferences to a cantonal elite preference measure using government composition data. Appendix A4 provides more detailed information on how we derive the preference measures for the voters and the elite with MRP.

Our empirical design overcomes three major problems of the literature on the institutional effects of direct democracy. First, most articles investigate whether specific policies (e.g., tax levels) correlate with variation in direct democracy (Feld and Kirchgässner 2000; Matsusaka 2004). The validity of these analyses hinges on the implicit (and potentially implausible) assumption that voters' preferences are constant between the units of analysis. Second, studies analyzing voters' preferences typically measure the preferences and policy outcomes on different scales (Achen 1978; Erikson, Wright, and McIver 1993; Hug 2011; Matsusaka 2001). Third, many articles investigate only a single or a few policy areas, which might bias the findings (Gerber 1996; Lax and Phillips 2009a). We overcome the mentioned problems by estimating, for various policy areas, the preferences of the voters and the elite on the same (binary) metric as the policy outcomes. The measures for policy congruence and for the elite-voter preference deviation are consistent because of the common binary metric.

\section{EMPIRICAL ANALYSIS}

The core idea of policy congruence is that the actions of representatives are in line with the majority positions of voters. Following our definition of policy congruence, we analyze an outcome variable that codes whether a policy in a given canton is supported by the majority of the citizens or not (Lax and Phillips 2009a, 2012). We rely on this binary measure of policy congruence for conceptual and methodological reasons. Conceptually, policy congruence is not about the degree of support for a policy in the electorate. Rather, the basic question is whether or not a majority of voters is in favor of a

\footnotetext{
15 We chose the combination of explanatory variables on the cantonal level in the response model $(\mathbf{X})$ that minimize AIC and BIC (see footnote 13).
} 
policy. ${ }^{16}$ Methodologically, the dichotomy of the policies (i.e., they are either in place or not) is important because this allows us to measure policies and preferences on a common (binary) metric. This common metric is also reflected in the binary coding of policy congruence, which essentially combines the measures of the preferences of voters and the policy outcomes. Of course, the binary measurement of policies and policy congruence simplifies political realities. However, we believe that the costs of reducing complexity are more than compensated by the gains in conceptual clarity and methodological rigor.

The two main explanatory variables of the theoretical model presented in the Theory section are the costs of using direct democratic rights and the elitevoter preference deviation. To measure the costs of direct democracy usage, we rely on a widely used index of direct democratic rights (Freitag and Vatter 2006; Frey and Stutzer 2000; Stadelmann-Steffen and Freitag 2011; Stadelmann-Steffen and Vatter 2011). The index measures how difficult it is to use direct democracy, for example, in terms of the time granted to collect signatures and the number of signatures required (Frey and Stutzer 2000; Stutzer 1999). In line with the theoretical model, the direct democracy measure accounts for the usage costs for citizens to successfully call for a referendum or to launch an initiative (high values on the index imply low costs and thus more direct democracy). Appendix A5 shows the variation of the direct democracy index and compares the values of the Swiss cantons to the level of direct democracy in California. In comparative perspective, Swiss cantons vary between a low level of direct democracy and a very high level. The elite-voter preference deviation is measured as the absolute distance between the government's and the voters' preferences in case they hold opposing majority opinions (if they agree, the variable is set to 0 ).

As control variables, we use measures of the clarity of the government and voter opinions, coded as the absolute deviation from 0.5 , because the findings on the preference-deviation variable could be driven by extreme voter or government opinions (Lax and Phillips 2009a). In addition, we control for a number of institutional, economic, cultural, and structural variables. We include measures of the electoral threshold and the power of the legislator vis-à-vis the government, expecting that low electoral thresholds and powerful legislators are associated with higher policy congruence (Bochsler and Bousbah 2015; Kaiss 2010). Furthermore, we control for economic, cultural, politi$\mathrm{cal}$, and structural heterogeneity among the cantons by modeling GDP per capita, population size, the strength of the Swiss People's Party (SVP), and the share of German speaking citizens. Particularly, the language variable is of importance because direct democracy is more comprehensive in the German speaking part of Switzerland. Finally, we model a dummy variable that codes for each canton and policy whether there has

\footnotetext{
${ }^{16}$ We coded whether a policy was cantonal law when the surveys
} were conducted (that is, at the end of 2012) been a public vote or not in the three years prior to the surveys (that is, 2010-2012). ${ }^{17}$ This direct democracy in use measure is important because scholars differentiate between the effects of direct democracy in use (policies are decided on the ballot) and the effects of the threat of a possible referendum or initiative on the behavior of legislators. As it is conventional in the literature and consistent with our theoretical model, we rely on an institutional measure on the usage costs of direct democratic rights as our main explanatory variable (Gerber 1996; Matsusaka 1995; Stutzer 1999). However, including the dummy variable on the actual use of direct democracy allows us to analyze whether policies are primarily congruent because voters have made decisions at the ballot box.

We analyze cross-nested hierarchical probit models with random effects for policies and cantons. The first model includes the institutional direct democracy measure. The estimates reported in Table 1 confirm the positive and significant effect of direct democratic institutions on policy congruence. In the second model, we introduce the preference deviation variable. The findings show, as suggested by the work of the representation literature, that preference deviation is a significant predictor of policy incongruence: the more the people and the government disagree, the less likely is policy congruence. In the third model, we empirically test the main prediction of the theoretical model-namely, that the positive effect of direct democracy increases, as the preference deviation between the voters and the government becomes larger. To investigate that prediction, we include an interaction between the preference deviation and direct democracy. Model 3 includes all three explanatory variables that are motivated by the theoretical model. As expected, the interaction term is positive and significant. This finding supports our main prediction that the positive effect of direct democracy increases, the more the preferences of the voters and the elite are at odds (a hypothesis test for the significance of the interaction term is presented below). The empirical findings also confirm the prediction that direct democratic institutions have no effect on policy congruence, if the government and the people both support or reject a policy (i.e., DEVIATION $=0$ ).

In order to test our main hypothesis against alternative explanatory factors, the full Model 4 includes all controls as well as the direct democracy in use variable. The results of Model 4 are essentially identical to the estimates of Model 3. Most importantly, the positive and significant effect of the interaction term corroborates the main prediction of the model that the conducive effect of direct democracy on policy congruence increases as a function of the degree of the dissonance between the government and voter preferences. Model 4 further shows that government and voter opinion clarities are significant predictors of policy congruence, but controlling for extreme voter or government opinions does not alter the findings

\footnotetext{
17 Own coding based on data from the Centre for Research on Direct Democracy (c2d). The findings are the same if we extend the lag to five or more years.
} 


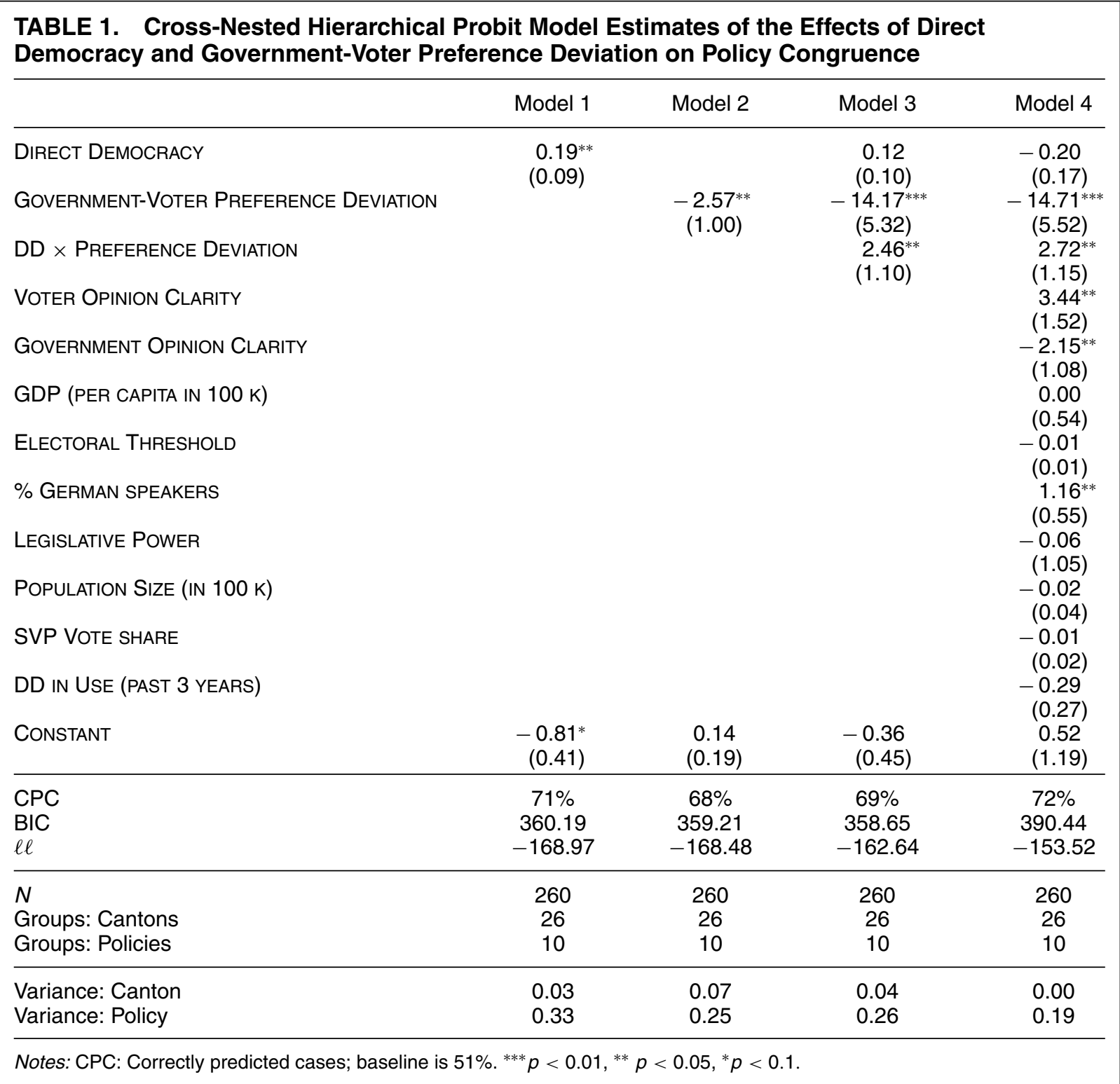

on the preference-deviation variable. The only other significant predictor is the share of German speakers (policy congruence is more widespread in German speaking cantons). Finally, the estimates of the direct democracy in use variable suggest that it does not matter for policy congruence whether the electorate has voted on an issue or not (note that the model also includes the usage costs of direct democratic rights and the interaction effect). According to this nonfinding, policy congruence is not primarily driven by the usage of direct democracy, which is consistent with both our theoretical model and the conventional view in the literature (Gerber 1996; Matsusaka 1995). Appendix A6 reports robustness checks using alternative measures of direct democracy and of the preference deviation between the government and the voters. The results for the main explanatory variables are robust.

Besides the robustness to alternative specifications, a further concern related to the validity of the pre- sented findings is the potential endogeneity that policy congruence influences (in reverse model direction) the extent of direct democracy in the cantons, which would invalidate the above discussed inferences. To out rule potential endogeneity, we run 2SLS IV estimation using the degree of direct democracy at the end of the 19 th century as an instrument for direct democratic institutions in 2010. The analysis relies on the Historical Direct Democracy Index, which dates back to 1803 (Leemann 2014). The instrument fulfills the exclusion restriction, when the degree of direct democracy in the 19 th century is independent from the error term of the second-stage regression. This assumption is violated in case of reverse causation, or if the historical institutions affect the outcome through another causal pathway than the instrumented variable. The former is unproblematic because policy congruence today cannot be the cause of institutional settings of the 19th century. The latter is relevant when the historical institutions affect 


\begin{tabular}{|c|c|c|c|}
\hline & $\begin{array}{l}\text { Model } 6 \\
\text { 1st Stage }\end{array}$ & $\begin{array}{l}\text { Model } 3 \text { IV } \\
\text { 2nd Stage }\end{array}$ & $\begin{array}{l}\text { Model } 4 \text { IV } \\
\text { 2nd Stage }\end{array}$ \\
\hline Direct Democracy (19th CentuRY) & $\begin{array}{l}0.43^{* * *} \\
(0.12)\end{array}$ & & \\
\hline Government-Voter Preference DeVIATION & $\begin{array}{l}2.16^{* *} \\
(0.98)\end{array}$ & $\begin{array}{c}-15.67^{* *} \\
(6.10)\end{array}$ & $\begin{aligned}-15.00^{* *} \\
(6.13)\end{aligned}$ \\
\hline DIRECT DEMOCRACY & & $\begin{array}{r}0.22^{*} \\
(0.13)\end{array}$ & $\begin{array}{c}0.02 \\
(0.19)\end{array}$ \\
\hline DD $\times$ PREFERENCE DEVIATION & & $\begin{array}{l}2.79^{* *} \\
(1.27)\end{array}$ & $\begin{array}{l}2.79 * * \\
(1.28)\end{array}$ \\
\hline VOTER OPINION CLARITY & & & $\begin{array}{l}3.19^{* *} \\
(1.56)\end{array}$ \\
\hline GOVERNMENT OPINION CLARITY & & & $\begin{array}{r}-1.51 \\
(1.12)\end{array}$ \\
\hline GDP (PER CAPITA IN $100 \mathrm{~K}$ ) & & & $\begin{array}{c}0.24 \\
(0.64)\end{array}$ \\
\hline ELECTORAL THRESHOLD & & & $\begin{array}{r}-0.01 \\
(0.01)\end{array}$ \\
\hline \% GERMAN SPEAKERS & & & $\begin{array}{c}0.73 \\
(0.52)\end{array}$ \\
\hline LEGISLATIVE POWER & & & $\begin{array}{c}0.02 \\
(1.07)\end{array}$ \\
\hline POPULATION SIZE (IN 100 K) & & & $\begin{array}{r}-0.00 \\
(0.03)\end{array}$ \\
\hline SVP VOTE SHARE & & & $\begin{array}{r}-0.00 \\
(0.02)\end{array}$ \\
\hline DD IN USE (PAST 3 YEARS) & & & $\begin{array}{r}-0.26 \\
(0.27)\end{array}$ \\
\hline CONSTANT & $\begin{array}{l}2.54^{* * *} \\
(0.41)\end{array}$ & $\begin{array}{c}-0.78 \\
(0.58)\end{array}$ & $\begin{array}{r}-0.59 \\
(1.35)\end{array}$ \\
\hline$R^{2}$ & 0.48 & & \\
\hline $\mathrm{BIC}$ & & 340.71 & 379.36 \\
\hline$\ell \ell$ & & -153.79 & -148.17 \\
\hline$N$ & 25 & 250 & 250 \\
\hline Groups: Cantons & & 25 & 25 \\
\hline Groups: Policies & & 10 & 10 \\
\hline Variance: Canton & & 0.03 & 0.02 \\
\hline Variance: Policy & & 0.30 & 0.28 \\
\hline
\end{tabular}

a variable that is not modeled in the second stage, but influences the outcome even after controlling for all other explanatory factors. We cannot think of such an alternative causal pathway.

To asses the strength of the instrument, we use the $F$ statistic of the instrument in the first stage model. The direct democracy index from the end of the 19th century achieves an $F$ value of 12.45 , which is clearly higher than the conventional threshold of 10 (Stock, Wright, and Yogo 2002).$^{18}$ We perform 2SLS IV estimation for the theoretically motivated Model 3 as well as for the

\footnotetext{
18 We account for the uncertainty of the first-stage model in the estimation by simulating 500 first-stage predictions, which are then translated into second-stage estimations. Because the canton of Jura did not exist before 1973, we cannot use the instrument for this case and have therefore dropped the canton from the analysis.
}

full Model 4 of Table 1 (Angrist and Pischke 2008). Table 2 reports the findings of the first- and secondstage models. The estimates are by and large the same as the ones discussed above. Most importantly, the interaction effect between direct democracy and the government-voter preference deviation is clearly positive and significant in both models, corroborating the main argument of this analysis.

Figure 2 illustrates the size of the interaction effect relying on the estimates of Model 3 of Table 1. Reported are the predicted probabilities of policy congruence, including the uncertainty of the predictions (Gelman and Hill 2007; Herron 1999). The $x$ axis displays the government-voter preference deviation and the $y$ axis the predicted probability of policy congruence. The solid line reports the predictions for a very low level of direct democracy (limited DD) and the dotted line for a 
FIGURE 2. Interaction Effect of Direct Democracy and the Government-Voter Preference Deviation on Policy Congruence

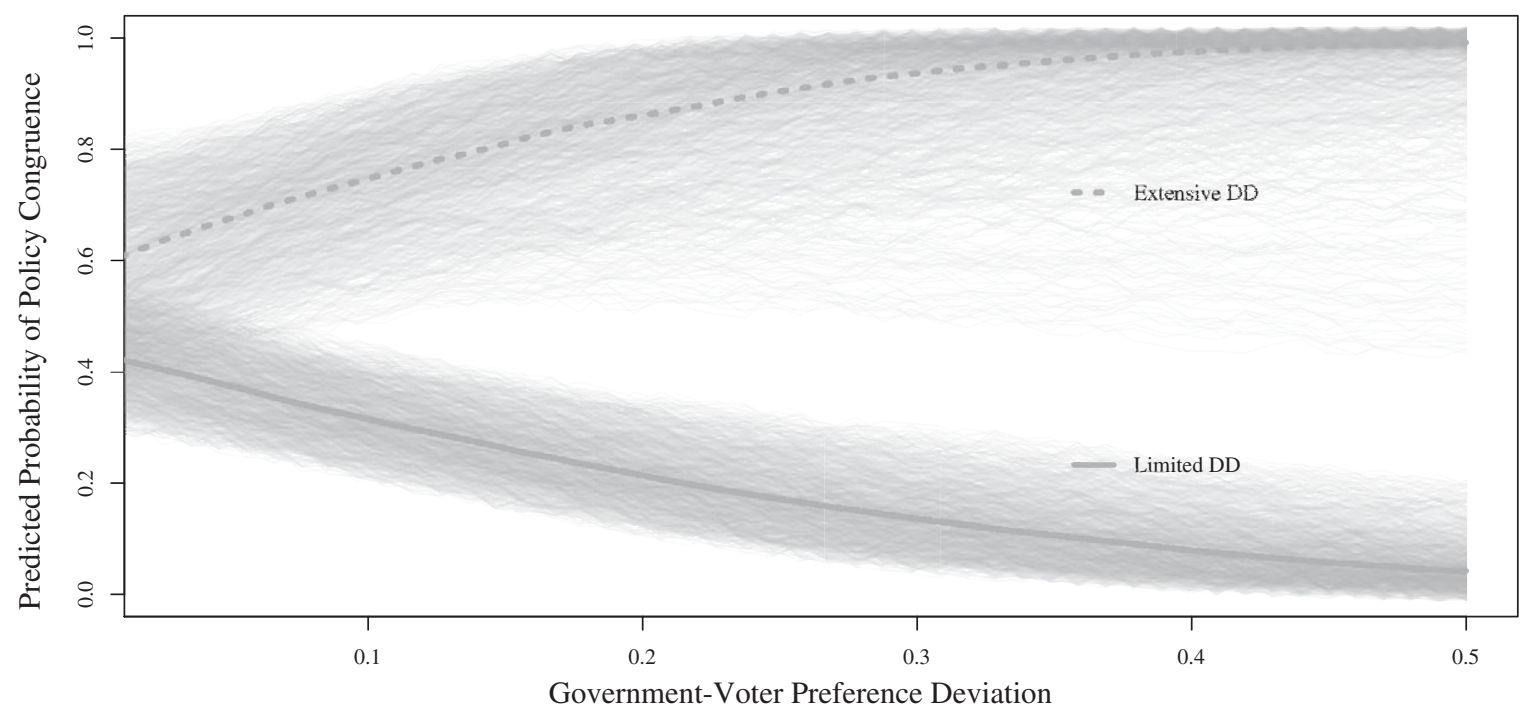

hypothetical canton with high values of direct democracy (extensive DD). The increase in direct democracy from limited to extensive has two effects: first, citizens in cantons with more direct democracy more often get what they want. The probability of policy congruence is always higher, no matter how large the preference deviation is. For example, for a small value of the preference deviation (0.00), the difference in predicted probabilities of policy congruence between limited and extensive direct democracy is about $16.8 \%$ (95\% CI: $[-0.03,35.18])$, while this measure increases to $40.7 \%(95 \% \mathrm{CI}:[16.86,58.28])$ for a slightly more sizable preference deviation (0.10).

Second, the differences in the predicted probabilities also document the interaction effect between direct democracy and the preference deviation: the difference in the predicted probabilities between limited and extensive direct democracy increases as the deviation becomes larger (that is, the effectiveness of adding direct democratic rights on policy congruence grows, the larger the preference deviation). The interaction effect is clearly significant, as the confidence interval of the difference in the differences shows $(\Delta(\Delta \hat{p})=24.38 \%$ (95\% CI: [2.52, 43.42])) (Brambor, Clark, and Golder 2006; Tsai and Gill 2013). In short, the robust and significant results support the main prediction of our theoretical model-namely, that the positive effect of direct democratic institutions increases, as the elitevoter preference deviation becomes larger. ${ }^{19}$

\footnotetext{
${ }^{19}$ A potential objection against the hypothesis tests is that we underestimated the full uncertainty in Models 1 to 4 because some explanatory variables are measured with uncertainty (the preference variables) (see, e.g., Lewis and Linzer 2005). To account for the full uncertainty, we estimate the same models relying on 1,000 posterior draws of the preference predictions (first stage), rerun the models for each draw, and save 30 draws of the second-stage posterior. The resulting sum of draws reflects both the uncertainty from measurement
}

Figure 2 also shows that the effect of the preference deviation on policy congruence turns from positive to negative when we change the decision making from strongly to limited direct democratic (the line goes down). This may need further explanation. In general, a large preference deviation between the elite and the citizens means that the preference of the electorate is not well represented in policy making. Bad representation is bad for policy congruence. The model-based predictions for a system with very limited direct democratic rights show the dominance of that effect. The slope falls because the negative effect of the preference gap on policy congruence dominates. In other words, the costs of using direct democracy become too high to correct the growing preference gap. This does not apply, however, for a political system with a high level of direct democracy. In such a system, a large elite-voter preference deviation is conducive for policy congruence because the elites know that voters are so strongly opposed to their position that the intervening factors (i.e., the imprecision of the preference signal and the usage costs of direct democratic institutions) become inconsequential. Thus, in strongly direct democratic polities, a large elite-voter preference deviation empowers the electorate to overturn the deviating preferences of the elite.

\section{DIRECT DEMOCRACY AND THE POLITICAL CONFLICT STRUCTURE}

The finding that the effect of direct democracy on policy congruence depends on the preferences of the elite and the voters may explain why some scholars have found evidence that direct democracy leads

(first stage) and the variation in the estimated coefficients (second stage). This approach still yields a significant difference of differences estimate (on the $0.05 \alpha$ level). 
to more policy congruence (Gerber 1996, 1999; Matsusaka 2004, 2010), while others could not replicate that result (Lascher, Hagen, and Rochlin 1996; Lax and Phillips 2009a, 2012; Tausanovitch and Warshaw 2014). Direct democracy has no unique and constant effect on policy congruence. The main finding of our analysis - that direct democracy becomes more conducive for policy congruence the more the preferences of the people and the elite deviate - raises the question of when we would expect large preference gaps and thus strong effects of direct democracy.

Representation scholars argue that competitive and fair elections constantly minimize the elite-voter preference gap through selection and sanctioning: citizens (s)elect representatives with similar preferences and sanction incumbents by not re-electing them if their behavior in office deviates from the majority will of the electorate (Mansbridge 2009; Schumpeter 1942). Scholars of direct democracy, however, have emphasized that this electoral mechanism cannot democratically accommodate all policies in a multidimensional policy space. Here lies the powerful property of direct democracy: referendums and initiatives allow it to unbundle policy issues (Besley and Coate 2008). In other words, citizens can also influence the outcomes of policies that are not democratically accommodated by elections, when they live in representative democracies that are complemented with direct democratic institutions. $^{20}$

The effectiveness of the direct democratic and the representative mechanisms of policy congruence thus depend on the political environments. Politics in modern democracies is typically dominated by a main political conflict dimension on the left-right spectrum. In a polity with a one-dimensional political conflict structure, competitive and fair elections should regularly minimize the elite-voter preference gap for the overwhelming majority of policies. Adding direct democratic institutions in that case would only matter for the rare policies not covered by the main political conflict dimension. Accordingly, the effects of direct democracy on policy congruence should be limited because we expect only rare and small elite-voter preference gaps. An example of a polity with a one-dimensional policy space is the United States in the last 130 years, where a large share of issues aligned on the liberal-conservative dimension (McCarty, Poole, and Rosenthal 2006).

Unlike in the United States, political conflict in most European countries spans over a multi-

\footnotetext{
${ }^{20}$ Direct democratic systems and representative democracies are often described as distinct models (Held 1996). Kriesi $(2005,6)$, however, argues that for empirical research, this distinction is "overdrawn" because we usually analyze democratic polities that are enriched with direct democratic elements. This is also true for Swiss cantons, which are representative systems complemented to varying degrees by direct democratic institutions (see Appendix A5). Most scholars argue that adding direct democratic institutions to representative democracies fosters the participatory capacity of voters (Kriesi 2005; Matsusaka 2005). Stadelmann-Steffen and Freitag (2011, 527) make the contrasting point that the combination of representation and direct democracy "offers the least advantageous environment for the development of civic engagement."
}

dimensional policy space (Kriesi et al. 2008). ${ }^{21}$ The dominant (first) dimension usually covers the classic left-right economic conflict, while the second-ordered dimensions include, among others, moral and cultural policy questions (Kitschelt and Rehm 2014). If parties compete primarily along the economic (distributional) dimension, we would expect elections to accomodate the policies on the first dimension. In that case, direct democratic institutions should be powerful in aligning second-ordered policies with the majority preference of the electorate. Taken together, the insights of the representation literature and the unbundling argument suggest that direct democratic institutions are effective democratic correctives for policy questions not covered by the dominant (first) dimension.

We find empirical evidence supporting the argument that the effectiveness of direct democracy depends on the political conflict structure. First, the majority of initiatives raised over the last 50 years in Switzerland were concerned with policies on the second-ordered dimension (Leemann 2015). Second, according to the data of this study, the preference gap between the elite and voters is larger for policies not covered by the (dominant) first dimension. Third, the analysis of the data also suggests that the effect of direct democracy on policy congruence is driven by the policies that are not covered by the first dimension. As a cautionary note, we would like to emphasize that the dimensionality analysis of our data relies on the strong assumption that the political conflict structure is the same in all the 26 cantons. The findings are thus more suggestive than conclusive (see Appendix A7 for a detailed discussion of the dimensionality analysis and its limitations).

In sum, we conclude that the insights of previous research and the analysis of our data point in the same direction: whether it is-from a policy congruence perspective-advisable to introduce direct democratic institutions as democratic correctives to representative systems depends on the political conflict structure (i.e., the dimensionality of the political space). This broader institutional implication of our analysis illustrates that direct democratic institutions interact in a complex way with the key elements of representative democracies.

\section{CONCLUSION}

This article presented a theoretical model of how direct democratic institutions achieve policy congruence. The formal model showed that the positive effect of direct democracy on policy congruence increases as the elite-voter preference deviation grows. This finding suggests, in contrast to the argument of representation scholars, that "bad" representation is in direct democratic systems conducive for policy congruence, mainly because it provides a clear signal that the elite and the voters disagree on some policy issue. For the empirical analysis, we relied on original elite and voter survey data for 10 different policies of Swiss cantons,

\footnotetext{
$\overline{21}$ We rely on this stylized distinction between one- and twodimensional polities for clarifying the argument. Political competition occurs on multiple dimensions in all democratic systems.
} 
which provide unique variation on direct democratic institutions. The specification of the empirical model followed directly from the theoretical analysis, and the empirical results were as predicted and robust across different specifications (also in models with an instrument for the institutional variable). To the best of our knowledge, this analysis is the first policy congruence study that investigates theoretically and empirically the connection between direct democratic institutions and the preferences of the voters and the elite over multiple policy areas.

Some points of concern need to be discussed. Objections against the formal model might be that the equilibrium predicts the absence of referendums and that the government always loses direct democratic votes. Both are obviously not the case in the real world. However, we believe that this does not limit the insights the model provides in respect to the direct democratic mechanism of policy congruence we have analyzed. According to the theoretical model and empirical findings, the main democratic power of direct democracy is that the political elite anticipate preference deviations and, in the case that voters have extensive direct democratic rights, follow the position held by (the large) majority of voters. This is often referred to as the indirect effect of direct democracy. Of course, policy outcomes can also become congruent through the use of direct democratic rights (that is, the direct effect of direct democracy). However, the empirical results, in support of the theoretical model, do not suggest that this direct effect of direct democracy on policy congruence is strong.

The model's discrete policy space might be subject to criticism too. We argue that for direct democratic decision making, this simplification is appropriate because voters face a discrete choice at the ballot box. Nevertheless, we would like to emphasize that the political elite has nonbinary room to maneuver for shifting away from voters' preferences, particularly in the implementation of laws. The discrete policy space might thus be an inappropriate simplification for some stages of the policy cycle, like the implementation stage, but less so for the decision-making part we analyzed in this study. In any case, the fact that the political elite has some discretion in the implementation of policies highlights the limitations of direct democratic control (Gerber et al. 2000). A further question in that regard is to what extent well-organized and heavily funded interest groups control the use of direct democratic institutions and the content of direct democratic campaigns. The more this is the case, the less accurate is our theoretical distinction between the preferences of the elites and the voters. This is less problematic in the smallsized Swiss cantons, where these kind of interest groups hardly exist, as compared to U.S. states like California (Broder 2000).

Hug (2009) forcefully argues in a recent critique of the literature on direct democracy that further research is needed to better understand how direct democratic institutions interact with the key elements of representative democracy. As far as policy congruence is concerned, we believe our analysis provides a nuanced account of how adding participatory elements to representative democracies affects democratic performance. The presented findings show that the extent to which direct democratic institutions lead to more policy congruence depends on the elite-voter preference deviation. More specifically, the democratic effect of direct democracy is most effective in cases of "bad" representation. Finally, the discussion of the institutional implications of the findings suggests that initiatives and referendums are most likely effective democratic correctives to representative systems in polities with multidimensional conflict structures.

\section{SUPPLEMENTARY MATERIAL}

To view supplementary material for this article, please visit http://dx.doi.org/10.1017/S0003055416000307

\section{REFERENCES}

Achen, Christopher, H. 1978. "Measuring Representation." American Journal of Political Science 22 (3): 475-510.

Angrist, Joshua D., and Jörn-Steffen Pischke. 2008. Mostly Harmless Econometrics: An Empiricist's Companion. Princeton, NJ: Princeton University Press.

Besley, Timothy, and Stephen Coate. 2008. "Issue Unbundling via Citizens' Initiatives." Quarterly Journal of Political Science 3 (4): 379-97.

BfS. 2012. Swiss Census Data (2000 Census). Neuchâtel: Swiss Federal Statistical Office.

BfS. 2013. Statistik der Nationalratswahlen (Election Results for the Lower Chamber). Neuchâtel: Swiss Federal Statistical Office. http://www.bfs.admin.ch/bfs/portal/de/index/themen/17/02/ blank/key/national_rat/parteienstaerke.html.

Bochsler, Daniel, and Karima Bousbah. 2015. "Competitive Consensus: What Comes After Consociationalism in Switzerland?" Swiss Political Science Review 21 (4): 654-79.

Brambor, Thomas, William Roberts Clark, and Matt Golder. 2006. "Understanding Interaction Models: Improving Empirical Analyses." Political Analysis 14 (1): 63-82.

Broder, David S. 2000. Democracy Derailed. New York: Harcourt.

Dahl, Robert A. 1971. Polyarchy: Participation and Opposition. New Haven, CT: Yale University Press.

Erikson, Robert S., Gerald C. Wright, and John P. McIver. 1993 Statehouse Democracy: Public Opinion and Policy in the American States. Cambridge, MA: Cambridge University Press.

Feld, Lars P., and Gebhard Kirchgässner. 2000. "Direct Democracy, Political Culture, and the Outcome of Economic Policy: A Report on the Swiss Experience." European Journal of Political Economy 16 (2): 287-306.

Freitag, Markus, and Adrian Vatter. 2006. "Initiatives, Referendums, and the Tax State." Journal of European Public Policy 13 (1): 89112.

Frey, Bruno S., and Alois Stutzer. 2000. "Happiness, Economy and Institutions." The Economic Journal 110 (466): 918-38.

Gelman, Andrew, and Jennifer Hill. 2007. Data Analysis Using Regression and Multilevel/Hierarchical Models. Cambridge, MA: Cambridge University Press.

Gelman, Andrew, and Thomas C. Little. 1997. "Poststratification Into Many Categories Using Hierarchical Logistic Regression." Survey Methodology 23 (2): 127-35.

Gerber, Elisabeth R. 1996. "Legislative Response to the Threat of Popular Initiatives." American Journal of Political Science 40 (1): 99-128.

Gerber, Elisabeth R. 1999. The Populist Paradox: Interest Group Influence and the Promise of Direct Legislation. Princeton, NJ: Princeton University Press.

Gerber, Elisabeth R., Arthur Lupia, Mathew D. McCubbins, and Roderick D. Kiewiet. 2000. Stealing the Initiative: How State Government Responds to Direct Democracy. Upper Saddle River: Prentice-Hall. 
Golder, Matt, and Jacek Stramski. 2010. "Ideological Congruence and Electoral Institutions." American Journal of Political Science 54 (1): 90-106.

Held, David. 1996. Models of Democracy. Stanford, CA: Stanford University Press.

Herron, Michael C. 1999. "Postestimation Uncertainty in Limited Dependent Variable Models." Political Analysis 8 (1): 83-98.

Hug, Simon. 2004. "Occurrence and Policy Consequences of Referendums. A Theoretical Model and Empirical Evidence." Journal of Theoretical Politics 16 (3): 321-56.

Hug, Simon. 2009. "Some Thoughts About Referendums, Representative Democracy, and Separation of Powers." Constitutional Political Economy 20 (3/4): 251-66.

Hug, Simon. 2011. "Policy Consequences of Direct Legislation Theory, Empirical Models and Evidence." Quality \& Quantity 45: 55978.

Kaiss, Stephanie. 2010. Das Verhältnis zwischen Exekutive und Legislative in den Schweizer Kantonen - Das Ausmass der Exekutivdominanz auf kantonaler Ebene. Zurich: University of Zurich.

Kastellec, Jonathan P., Jeffrey R. Lax, and Justin H. Phillips. 2010. "Public Opinion and Senate Confirmation of Supreme Court Nominees." Journal of Politics 72 (3): 767-84.

Kitschelt, Herbert, and Philipp Rehm. 2014. "Occupations as a Site of Political Preference Formation." Comparative Political Studies 47 (12): 1670-706

Kriesi, Hanspeter. 2005. Direct Democratic Choice. Lanham, MD: Lexington Books.

Kriesi, Hanspeter, Edgar Grande, Romain Lachat, Martin Dolezal, Simon Bornschier, and Timotheos Frey. 2008. West European Politics in the Age of Glabalization. Cambridge, MA: Cambridge University Press.

Lascher, Edward L., Michael G. Hagen, and Steven A. Rochlin. 1996. "Gun Behind the Door? Ballot Initiatives, State Policies and Public Opinion." Journal of Politics 58 (3): 760-75.

Lax, Jeffrey R., and Justin H. Phillips. 2009a. "Gay Rights in the States: Public Opinion and Policy Responsiveness." American Political Science Review 103 (3): 367-86.

Lax, Jeffrey R., and Justin H. Phillips. 2009b. "How Should We Estimate Public Opinion in The States?" American Journal of Political Science 53 (1): 107-21.

Lax, Jeffrey R., and Justin H. Phillips. 2012. "The Democratic Deficit in the States." American Journal of Political Science 56 (1): 148-66.

Leemann, Lucas. 2014. Origins of Direct Democracy and Cleavage Structure. Chapter 1, Ph.D. thesis. Columbia University.

Leemann, Lucas. 2015. "Political Conflict and Direct Democracy Initiative Use 1920-2011." Swiss Political Science Review 21 (4): 596-616.

Levendusky, Matthew S., Jeremy C. Pope, and Simon D. Jackman. 2008. "Measuring District-Level Partisanship with Implications for the Analysis of U.S. elections." Journal of Politics 70 (3): 73653.

Lewis, Jeffrey B., and Drew A. Linzer. 2005. "Estimating Regression Models in Which the Dependent Variable Is Based on Estimates." Political Analysis 13 (4): 345-64.

Lupia, Arthur. 1992. "Busy Voters, Agenda Control, and the Power of Information." American Political Science Review 86 (2): 390403.

Mansbridge, Jane. 2009. "A "Selection Model" of Political Representation." Journal of Political Philosophy 17 (4): 369-98.

Matsusaka, John G. 1995. "Fiscal Effects of the Voter Initiative: Evidence from the Last 30 Years." Journal of Political Economy 103 (3): 587-623.

Matsusaka, John G. 2001. "Problems with a Methodology Used to Evaluate the Voter Initiative." Journal of Politics 63 (4): 1250-56.

Matsusaka, John G. 2004. For the Many or the Few. How the Initiative Process Changes American Government. Chicago, IL: Chicago University Press.
Matsusaka, John G. 2005. "Direct Democracy Works." The Journal of Economic Perspectives 19 (2): 185-206.

Matsusaka, John G. 2010. "Popular Control of Public Policy: A Quantitative Approach." Quarterly Journal of Political Science 5: 13367

Matsusaka, John G., and Nolan M. McCarthy. 2001. "Political Resource Allocation: Benefits and Costs of Voter Initiatives." Journal of Law, Economics, and Organization 17 (2): 413-48.

McCarty, Nolan, Keith T. Poole, and Howard Rosenthal. 2006. Polarized America: The Dance of Ideology and Unequal Riches. Cambridge, MA: MIT Press.

Miller, Warren E., and Donald W. Stokes. 1963. "Constituency Influence in Congress." American Political Science Review 57 (1): 45-6.

Pacheco, Julianna. 2012. "The Social Contagion Model: Exploring the Role of Public Opinion on the Diffusion of Antismoking Legislation across the American States." Journal of Politics 74 (1): 187-202.

Park, David K., Andrew Gelman, and Joseph Bafumi. 2004 "Bayesian Multilevel Estimation with Poststratification: StateLevel Estimates from National Polls." Political Analysis 12 (4): $375-85$.

Romer, Thomas, and Howard Rosenthal. 1978. "Political Resource Allocation, Controlled Agendas, and the Status Quo." Public Choice 33 (4): 27-43.

Romer, Thomas, and Howard Rosenthal. 1979. "Bureaucrats versus Voters: On the Political Economy of Resource Allocation by Direct Democracy." Quarterly Journal of Economics 93 (4): $561-87$.

Schumpeter, Joseph A. 1942. Capitalism, Socialism, \& Democracy. New York: Harper.

Stadelmann-Steffen, Isabelle, and Markus Freitag. 2011. "Making Civil Society Work: Models of Democracy and Their Impact on Civic Engagement." Nonprofit and Voluntary Sector Quarterly 40 (3): 526-51.

Stadelmann-Steffen, Isabelle, and Adrian Vatter. 2011. "Does Satisfaction with Democracy Really Increase Happiness? Direct Democracy and Individual Satisfaction in Switzerland." Political Behavior 34 (3): 535-59.

Steenbergen, Marco R., and Bradford S. Jones. 2002. "Modeling Multilevel Data Structures." American Journal of Political Science 46 (1): 218-37.

Stock, James H., Jonathan H. Wright, and Motohiro Yogo. 2002. “A Survey of Weak Instruments and Weak Identification in Generalized Method of Moments." Journal of Business \& Economic Statistics 20 (4): 518-29.

Streunenberg, Bernard. 1992. "Referendum, Initiative, and Veto Power: Budgetary Decision Making in Local Government." Ky los 45 (4): 501-29.

Stutzer, Alois. 1999. "Demokratieindizes für die Kantone der Schweiz." Working Paper No. 23, Institute for Empirical Research in Economics, University of Zurich.

Tausanovitch, Chris, and Christopher Warshaw. 2013. "Measuring Constituent Policy Preferences in Congress, State Legislatures, and Cities." Journal of Politics 75 (2): 330-42.

Tausanovitch, Chris, and Christopher Warshaw. 2014. "Representation in Municipal Government." American Political Science Review 108 (3): 605-41.

Tsai, Tsung-han, and Jeff Gill. 2013. "Interactions in Generalized Linear Models: Theoretical Issues and an Application to Personal Vote-Earning Attributes." Social Sciences 2 (2): 91-113.

Vatter, Adrian. 2002. Kantonale Demokratien im Vergleich. Entstehungsgründe, Interaktionen und Wirkungen politischer Institutionen in den Schweizer Kantonen. Opladen: Leske und Budrich.

Warshaw, Christopher, and Jontahan Rodden. 2012. "How Should We Measure District-Level Public Opinion on Individual Issues?" Journal of Politics 74 (1): 203-19. 